\title{
CARTA INÉDITA DE UN VIAJERO INGLÉS POR LA ANDALUCÍA DE 1834
}

Jesús Díaz García

El documento que por primera vez sale a la luz en estas páginas, tanto en su versión original inglesa como en la traducción al español que la acompaña ${ }^{1}$, constituye solamente una modesta aportación al conocimiento de la historia de los paisajes y pueblos andaluces. Se trata de una carta familiar del viajero, diseñador y arquitecto Owen Jones, en la que, dada la intimidad de su estilo y su destinatario, se nos ofrece a mi entender una fiable y sincera descripción de los tipos, costumbres y caminos de la Andalucía de aquel año de 1834 .

Los juicios, impresiones y comentarios que recorren esta correspondencia resultan especialmente interesantes, porque testimonian la realidad socio-cultural de una Andalucía que permanece distinta y alejada tanto de la visión románticamente semidistorsionada de Whasington Irving, como, por otro lado, de aquella Andalucía derrotada que en su Manual para viajeros por Andalucía y lectores en casa nos describe el celebrado epítome de los viajeros ingleses del XIX, Richard Ford. La España negra, expoliada e inculta de Ford halla en Owen Jones la sosegada réplica de un artista de extraordinaria sensibilidad donde leemos una visión espontánea, ni elogiosa ni derrotista, de nuestras gentes y monumentos, sin la acritud ni la orientación tan particulamente negativa que la gran cultura y el espíritu crítico de Richard Ford nos proporciona; personaje este de Ford que parece haber recorrido nuestro país con un dolor de estómago que nunca le abandonara.

Aunque sólo sea sucintamente, conviene recordar algunos rasgos del perfil biográfico de Owen Jones. Nació en Londres en 1809, hijo de un generoso anticuario galés que llevó este mismo nombre, enamorado de la literatura galesa y

1 Agradezco a mi querido amigo Alberto García Ulecia, Catedrático de Historia del Derecho y magnífico poeta, el haberme puesto en contacto con el poseedor de esta Carta de Owen Jones, el generoso anticuario y amigo Joaquín Castro Ramos. Ellos deber ser reconocidos como los verdaderos mensajeros de estas palabras hasta ahora inéditas. 
gran mecenas. Owen Jones hijo fue un prestigioso arquitecto y diseñador de interiores en la Inglaterra victoriana, co-director del Crystal Palace, numerosas veces galardonado. En 1833 viaja por Oriente y visita parte de Grecia, Alejandría, El Cairo, Tebas y Constantinopla: quedaría para siempre enamorado de las formas y ornamentación del arte musulmán. En 1834 viene a Granada, con propósito de tomar apuntes y estudiar las riquezas artísticas del palacio, y volvería de nuevo tres años después. Su obra fundamental es The Grammar of Ornament (Londres, $1856,1865)$ pero entre su restante y numerosa bibliografía los andaluces le debemos aquella su gran y generosa aportación al conocimiento y preservación de nuestro patrimonio artístico que lleva por título Plans, Elevations, Sections, and Details of the Alhambra, publicada en 1836, y reeditada con ampliaciones en 1847-48, que el propio Jones pagó de su bolsillo. Contiene 101 ilustraciones en color, principalmente reproducciones de sus dibujos. Económicamente la publicación no fue precisamente un éxito.

Dejo al lector la interpretación del contenido de una carta donde cobran vida y movimiento los días y las horas de aquellos paisajes lejanos; el viaje en místico de Gibraltar a Málaga; las fiestas en la Alameda malagueña; las incidencias de su fatigoso y lento viaje hasta Granada en galera; los magníficamente cultivados viñedos a su paso; la belleza de las mujeres, y sus atavíos; la indumentaria y la gastronomía; la vega de Granada; Loja y Santa Fe; las cruces negras de los caminos; La Alhambra y sus habitantes... Pone Owen Jones, como se leerá seguidamente, un colofón entrañable a aquellos personajes semi-ficticios que pululan por los Cuentos de la Alhambra, de Washintong Irving: Owen Jones convive con la hurí-sirvienta Dolores y con Manuel Molina, y la Tía Antonia, y el peculiar cuentista Mateo Ximénez; y testifica cómo aquel idilio novelado por Irving entre los dos primos, Dolores y Manuel, acabó, así lo presumía el americano, en casamiento. Pero todo ello se oirá mejor en las palabras que Owen Jones escribiera el 16 de Mayo de 1834 desde sus aposentos de La Alhambra.

\section{La Alhambra}

Granada, 16 de Mayo de 1834

Querida madre y hermana:

Os escribí la última vez desde Gibraltar, una carta por tierra y la otra por el «St. Vincent». Al menos una de ellas os debe de haber llegado para esta fecha. Ahora ya me encontráis entre las paredes encantadas de La Alhambra. No dejamos Gibraltar hasta el atardecer del Sábado, día 30, cuando zarpamos rumbo a Málaga en un místico, con viento favorable. A la mañana siguiente, todavía temprano, estábamos costeando los ricos campos de esta parte de España, y hacia las 10 y media echamos el ancla en el puerto de Málaga, unos minutos demasiado tarde como para conseguir un práctico; así que fuimos obligados a perma- 


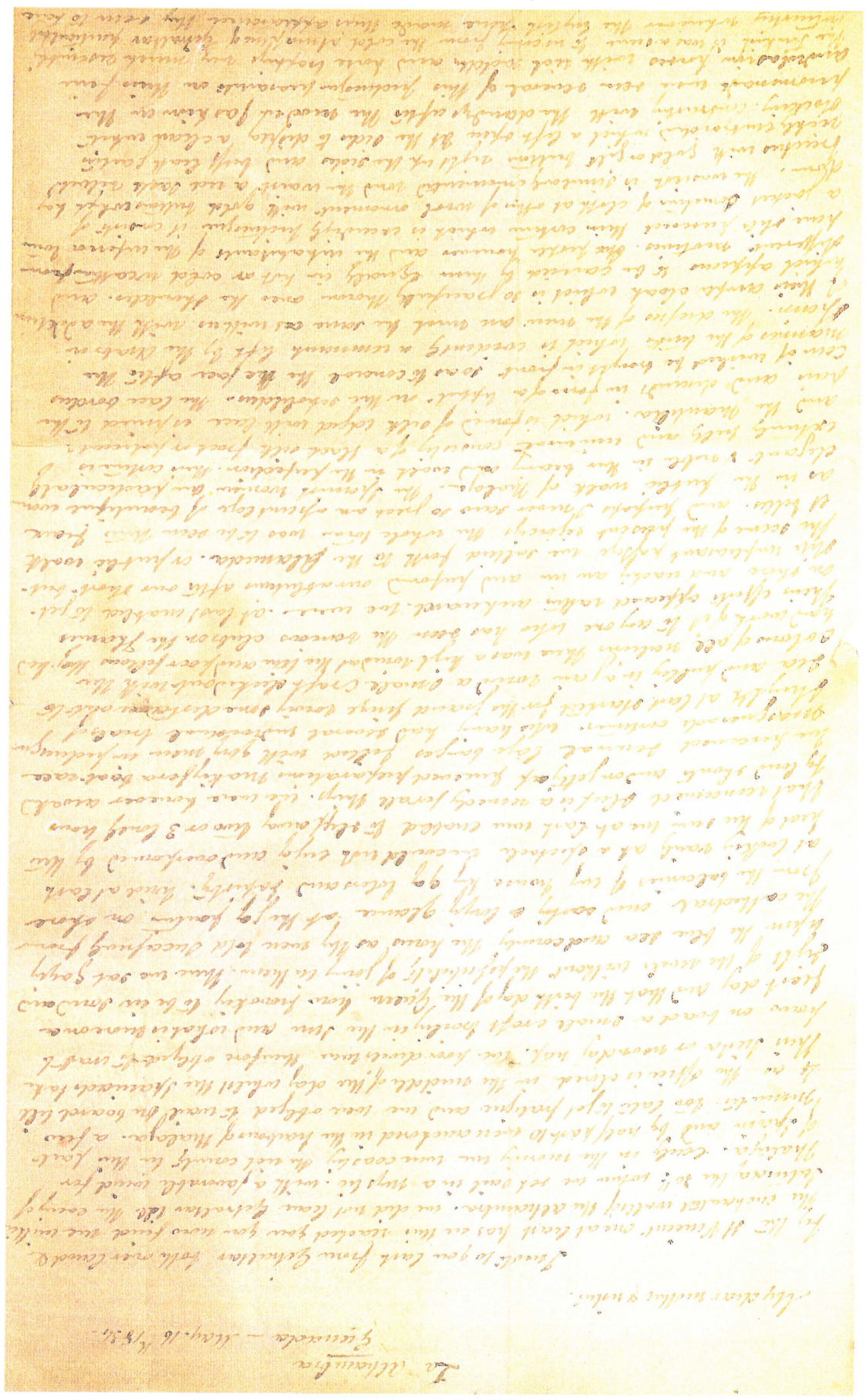




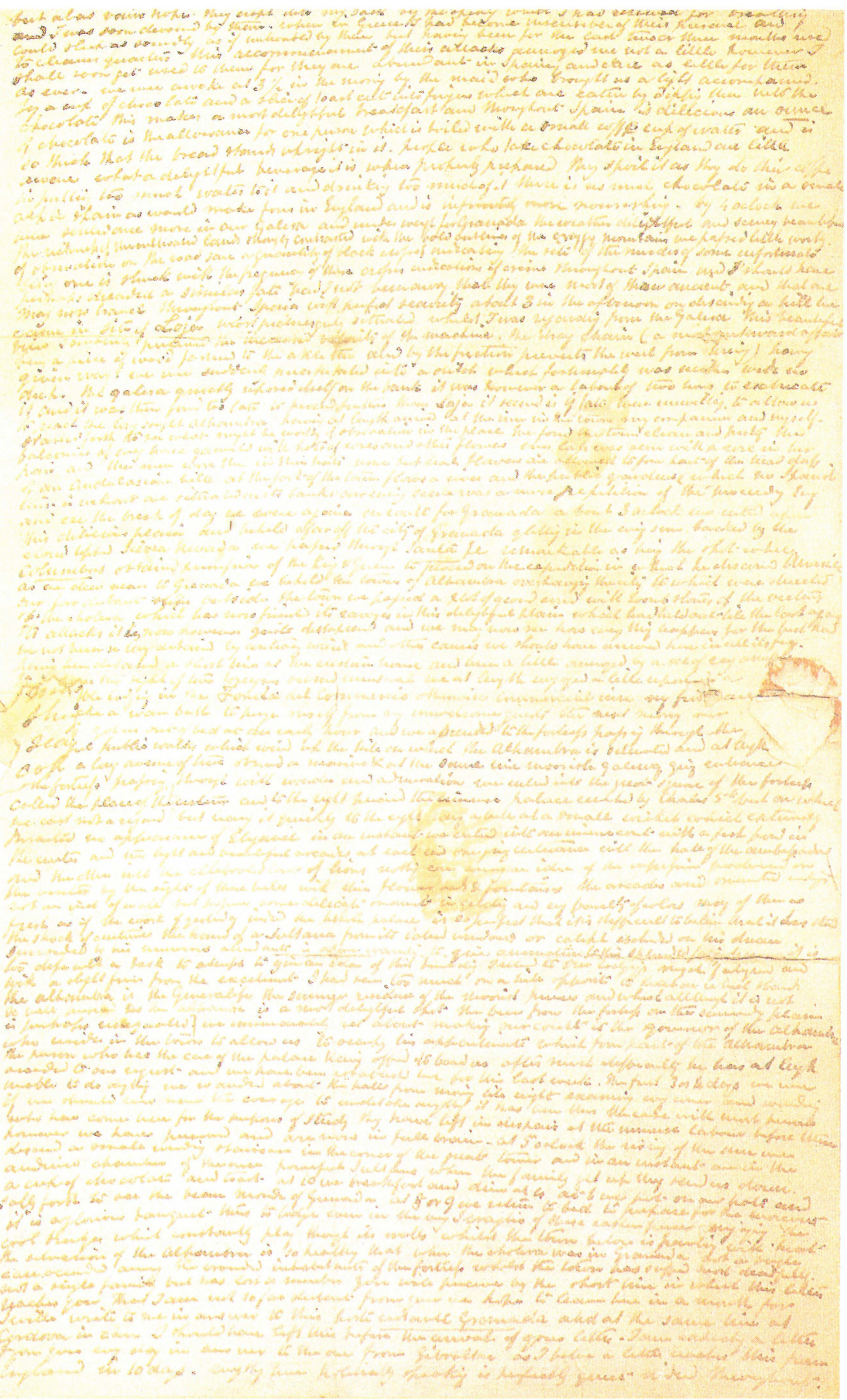




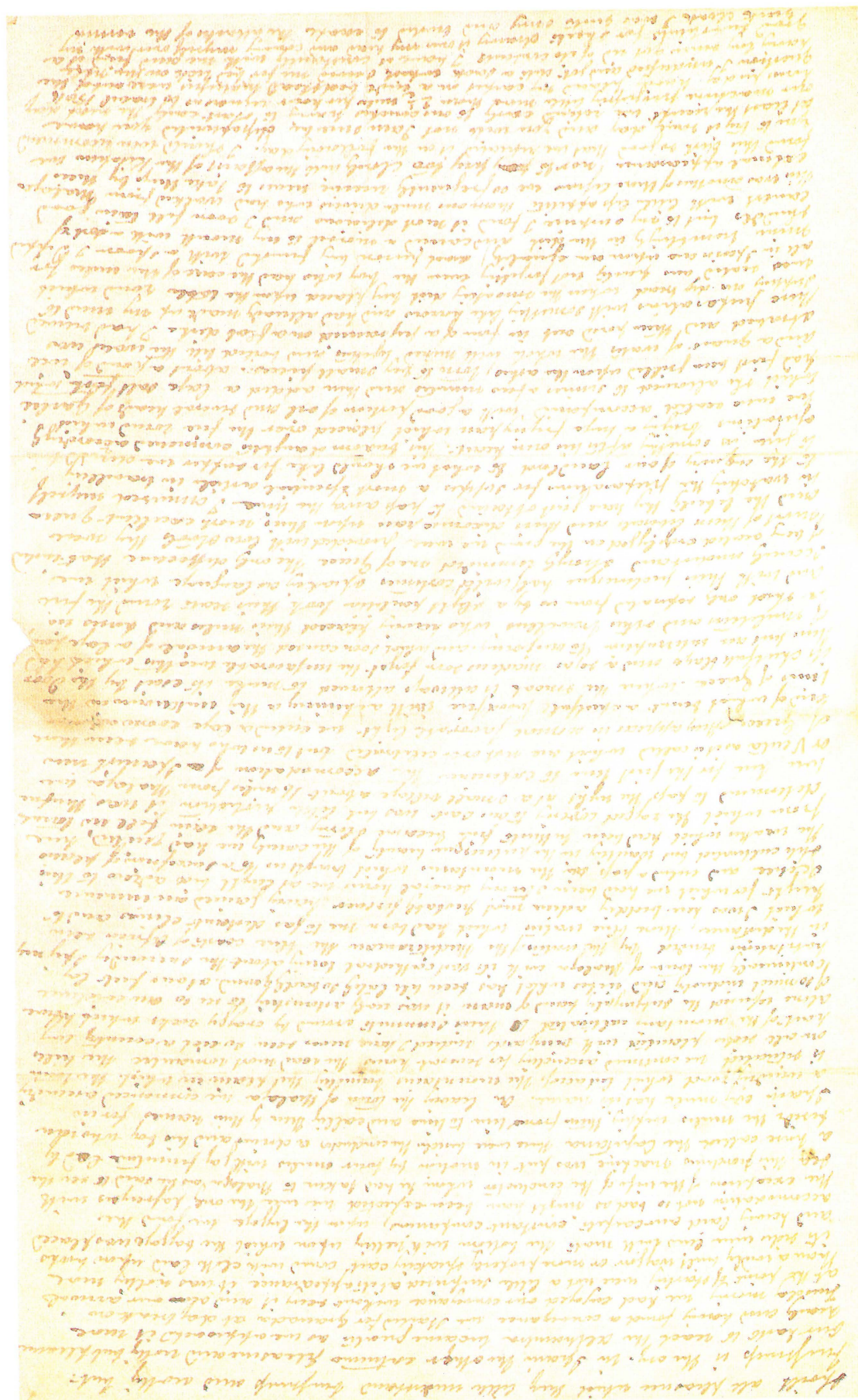




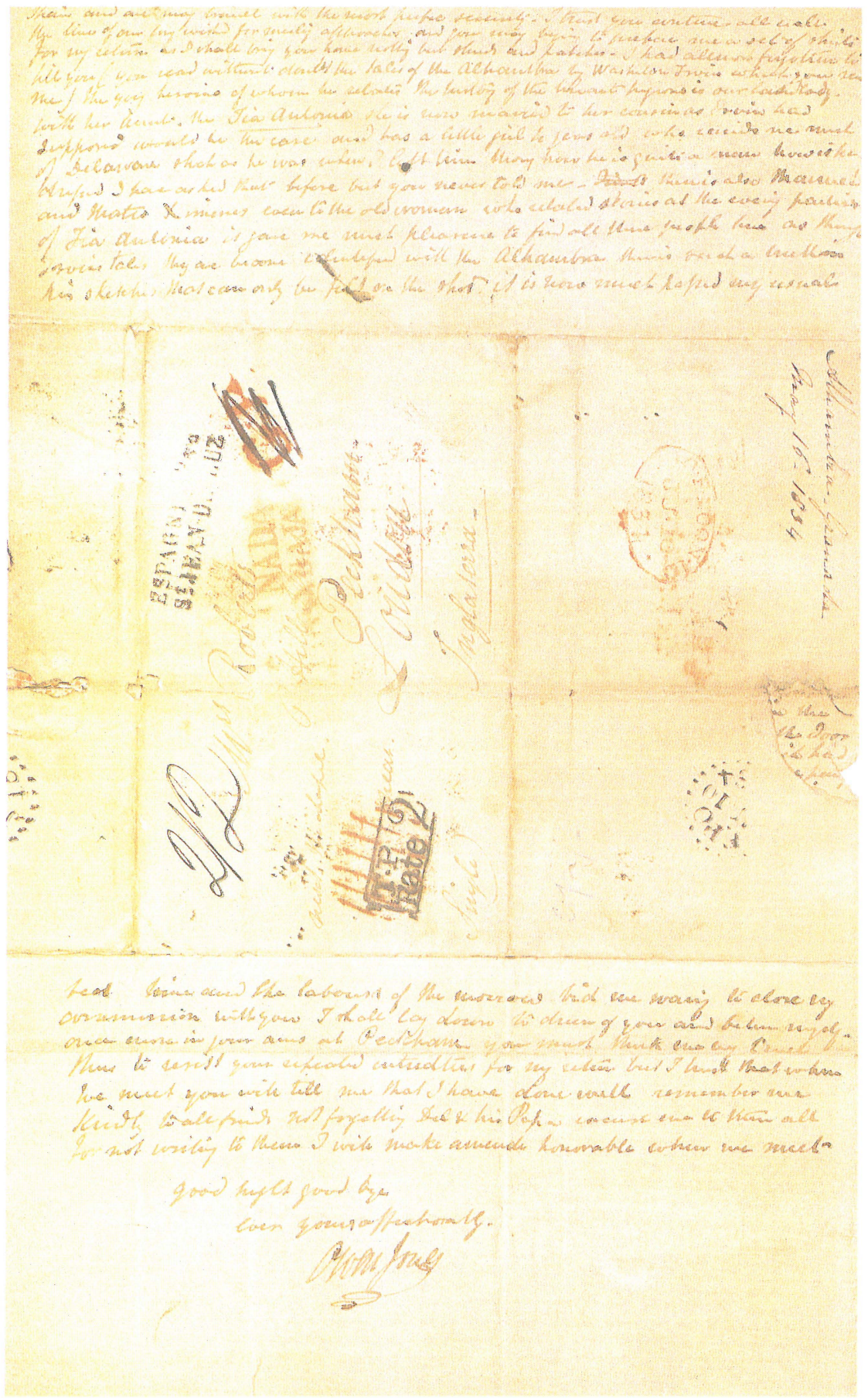


necer embarcados hasta las 4, ya que la oficina se cierra a mediodía mientras los españoles se echan su siesta o sueñecito de después de almorzar. De manera que, como pobres diablos, tuvimos que permanecer a bordo durante 6 horas, tostándonos al sol en nuestra pequeña embarcación, y lo que es más, en día de fiesta, puesto que era el día del cumpleaños de la reina. Cómo incita el estar oyendo y viendo a la gente divertirse y no poder unirse a las fiestas.

De modo que allí permanecimos, sentados y mirando el cielo azul, contando las horas conforme iban cayendo desde la catedral, contemplando anhelantes los alegres grupos de gente divirtiéndose en tierra. De los balcones de las casas colgaban banderas y tapices. Cansados finalmente de tanto mirar en vano y agobiados por el calor, al fin pudimos dormir dos o 3 solitarias horas, que el sueño siempre es un remedio para todo. Fuimos despertados, sin embargo, por un gran griterío y al incorporarnos observamos los preparativos que se hacían para una carrera de barcos. Se trataba de varias barcazas repletas de jóvenes ataviados con pintorescos disfraces quienes, tras varias demostraciones individuales de fuerza, al fin partieron en pos del gran premio, remando cierta distancia mar adentro y volviendo a puerto de nuevo tras darle la vuelta a una pequeña embarcación donde ondeaban banderas de todas las naciones. Había un fuerte viento durante la prueba, así que los pobres tuvieron que trabajar duro. Para todo aquel que ha visto los distintos clubs del Támesis en competiciones similares, los esfuerzos de estos muchachos le resultan bastante torpones.

Al fin se nos permitió bajar a tierra y, una vez en la posada, tras las abluciones correspondientes, después de nuestra corta mas sin embargo desagradable travesía, nos pusimos en marcha hacia la Alameda, o paseo público, encenario de la fiesta. La ciudad entera estaba allí congregada, guapos y guapas; yo quizás no haya visto nunca tan magnífica colección de mujeres bellas como en este paseo malagueño. La mujer española es especialmente elegante y noble en su porte y camina de manera perfecta. Su vestido consiste en una bata o falda de seda negra, y la mantilla, que es de seda, ribeteada de encajes, y que se prende al cabello de donde desciende sobre los hombros en forma de esclavina. Los ribetes de encaje pueden acercarse, si se desea, por delante de la cara y ocultarla, a la manera turca, lo que evidentemente es vestigio que los árabes dejaron en España. La indumentaria de los hombres es bastante similar a la nuestra, con la adición de la amplia capa que se echa suavemente sobre los hombros y que al parecer la llevan tanto en tiempo frío como caluroso. La gente del pueblo, sin embargo, y los aldeanos han mantenido su propia indumentaria, que es extraordinariamente pintoresca. Consiste en una chaqueta que a veces es de paño y otras de lana, adornada con botones color de oro que cuelgan un tanto. El chaleco esta adornado de manera similar. A la cintura llevan una faja roja, y los pantalones son de terciopelo con botones dorados a lo largo de las costuras laterales; llevan medias de liga. Contrastando con los dandis a la última moda, se veían por el paseo varios de estos pintorescos campesinos, montando sus magníficos caballos andaluces de ricas sillas de montar y ricos arreos y jaeces, bastante parecidos a los de los turcos. Era aquello todo un espectáculo, para nosotros que llegábamos del frío ambiente de Gibraltar, algo especialmente interesante. Dondequiera que han apare- 
cido los ingleses han acabado al parecer con todo lo placentero, cosa que no comprenden: negocios y sólo negocios es su santo y seña; en España hallamos el otro extremo: placeres y nada más que placeres.

Nuestra prisa por alcanzar La Alhambra se iba acrecentado conforme nos aproximábamos a ella y, habiendo encontrado un medio de transporte, partimos para Granada al amanecer del martes. Aquel medio de transporte nos había llenado de alegría aún sin verlo, pero cuando llegamos al sitio de la salida nos quedamos no poco sorprendidos ante su apariencia. No era más que un simple carro, o, hablando con propiedad, un carromato cubierto con telas sobre palos curvados. Los lados estaban limitados con esteras y el suelo era de red o malla, sobre las que se colocó el equipaje. Y una vez que extendimos nuestras alfombras, que nos acompañaban siempre, sobre el equipaje, encontramos el alojamiento no tan malo como se podría haber pensado. Eramos los únicos pasajeros, excepción hecha de la mujer del carretero, a quien, según nos dijo, había traído a Málaga para que viera el mar. Nuestra máquina se ponía en movimiento tirada por cuatro mulas de alegres arreos, encabezadas por una yegua de nombre Capitana. Además del carretero iban también un mozo de mulas y su hijo, que corrían junto a los animales, jaleándolos de cuando en cuando y llamándolos por sus respectivos nombres, porque en España cada mulo tiene su propio nombre. Al dejar la ciudad de Málaga, comenzamos a ascender por un camino que se retorcía hasta las montañas que enmarcan la llanura sobre la que se sitúa la ciudad. Continuamos subiendo durante varias horas por aquel camino tan romántico. Todas las colinas a nuestro paso estaban plantadas de viñedos. En verdad, yo nunca he visto un campo más rico. Cualquier parte de las montañas estaba cultivada hasta la misma cima, que estaba coronada por suelo pedregoso, el único que había rehusado someterse a la mano del hombre. Era realmente asombroso el contemplar tal muestra de laboriosidad y riqueza, tan mal gobernadas hasta hace poco. A nuestros pies continuaba extendiéndose la ciudad de Málaga, con su inmensa catedral dominando las pequeñas moradas, rodeadas por las aguas del Mediterráneo, con las azules costas de África en la lejanía; aguas aquellas que me habían llevado a mí a climas tan lejanos, aguas a las que yo ahora estaba diciendo adiós, probablemente para siempre. Habiendo alcanzado una inmensa cumbre, por la que llevábamos varias horas peleando cuesta arriba, por fin dijimos adiós a esta maravilla y nos metimos por un puerto de montaña que nos fue conduciendo a una serie de llanuras, también cultivadas pero sin la pintoresca belleza del campo que habíamos dejado atrás. Aquí el tiempo, que hasta entonces había sido excelente, se puso tormentoso y la lluvia empezó a caer a cántaros; de poca protección nos servían los jirones de tela que cubrían nuestro carromato. Consecuentemente, se decidió pasar la noche en un pequeño pueblo, como a unas 16 millas de Málaga. Aquí íbamos a saber por propia experiencia del alojamiento en una venta española, pues tal es el nombre que se da a nuestras «inns», que aunque no son precisamente muy célebres, sin embargo, para nosotros, que hemos visto las de Grecia, se nos aparecen con un tono mucho más favorable. Entramos en una sala muy espaciosa, en uno de cuyos extremos ardía alegremente un fuego de leña con una chimenea, cosa desconocida en las ventas griegas, en las que el humo halla siem- 
pre su salida por las puertas. Tan alentadora fogata nos hizo olvidar pronto el tiempo tan desapacible que nos había hecho interrumpir nuestro viaje y que pronto fue siendo la causa de la llegada de un gran número de muleros y otras gentes del camino, los cuales, una vez que metieron sus mulas y caballos en un cobertizo sólo ligeramente separado de donde estábamos, tomaron asiento alrededor del fuego y en aquella indumentaria medio primitiva y pintoresca, empezaron a hablar una lengua que apenas entendíamos, recordándome vivamente a Grecia, con la sola diferencia de su manera de sentarse, en el suelo y con las piernas cruzadas; a nosotros se nos había dado unos taburetes. La mayoría de ellos eran liberales y su conversación, para matar el tiempo, giró sobre las excelencias de su reina y sobre la libertad que acababan de conquistar. Yo me divertí contemplando los preparativos para la cena, asunto esencial en todo viaje. A la pregunta del ventero sobre qué queríamos de cena, nuestra respuesta fue que se lo dejábamos a su elección, algo que a él le gustara. Y seguidamente una hija suya, metidita en carnes, comenzó a moverse. Trajo una enorme sartén, que puso sobre el fuego que nos calentaba, echó un buen chorro de aceite y varias cabezas de ajo que dejó sofreirse lentamente durante unos minutos; después tomó un gran pescado salado, que previamente había sido asado sobre las brasas, y lo partió en pedacitos; añadió como medio kilo de arroz y poco más de un litro de agua, y, una vez todo bien mezclado, lo dejó hervir hasta que el agua fue absorbida. Y tras ello lo echó formando una pirámide sobre una fuente. Yo había venido observando todos los pasos de la faena con un sentimiento bastante parecido al horror, y ya me había decidido a comerme el pan sobrante del día. Entonces el humeante plato fue situado en la mesa a la que nuestro grupo se sentaba, sin olvidar siquiera al muchacho que cuidaba las mulas, porque en España todos son iguales; y se le dio una cuchara a cada uno. Metí la mía en la fuente temblando, y me llevé un trozo a la boca con una especie de escalofrío, pero, ante mi sorpresa, lo encontré verdaderamente delicioso, y enseguida me puse a ello con toda dedicación y casi tanto apetito como nuestro muleros, que habían venido andando desde Málaga. Esta fue otra de esas lecciones que uno recibe frecuentemente: nunca tomar las cosas por su apariencia externa ni husmear demasiado cerca los asuntos de la cocina. Hallamos esta comida tan deliciosa que la repetimos al día siguiente. Incluso os recomiendo que la probéis algún día, seguro que no os disgustará; bueno, al menos ya tenéis la receta.

Como teníamos que salir temprano al día siguiente, nos retiramos a la cama muy pronto. Dado que nuestra máquina sólo recorre poco más de dos millas y media por hora, ello requiere que viajemos 15 o 16 horas al día. Una vez que desplegué mi alfombra sobre las tablas de la cama — de colchones, ni hablar-, me desnudé y me metí en un saco que ya me sirvió como cama cuando estuve enfermo en el Nilo; ya hace tiempo que me deshice de todo lo que contenía y siempre lo llevo conmigo; lo encuentro un buen sustituto de las sábanas. Echándomelo sobre la cabeza y cubriéndome con mi capa griega, estaba bastante cubierto como para escapar de los ataques de pulgas y piojos, pero, ay de mi, esperanzas vanas, puesto que sigilosamente se metieron en mi saco por la abertura que yo había dejado para respirar, y en poco tiempo me estaban devorando. Cuando es- 
tuve en Grecia llegué a hacerme insensible a su existencia y podía dormir tan profundamente como si no me molestaran, pero habiéndome acostumbrado durante los dos o tres últimos meses a más limpias residencias, este volver a empezar de sus ataques me disgusta y no poco; sin embargo, me acostumbraré pronto ya que son bastante abundantes en España donde, como siempre, no se preocupan mucho de ellos. Nos despertó la sirvienta a las tres y media de la madrugada, trayéndonos una lámpara junto con una taza de chocolate y tostada que se come mojándola en el chocolate. Se trata de un desayuno muy agradable y es delicioso en toda España. Una onza de chocolate es la ración por persona, y se hierve en una pequeña taza de agua, y resulta tan denso que el pan se mantiene vertical dentro de él. La gente que toma chocolate en Inglaterra ignora cuan agradable es esta bebida cuando se prepara adecuadamente. Los ingleses lo estropean, como estropean también el café, al ponerle demasiada agua y tomar demasiado. Hay tanto chocolate en una taza de España como en cuatro de Inglaterra, y es infinitamente más nutritivo. A las cuatro ya estábamos sentados en nuestra galera y dirigiéndonos a Granada. El tiempo, magnífico; el paisaje, bellísimo. La rica tierra cultivada contrastaba claramente con los perfiles pronunciados y pedregosos de las montañas. Poco digno de atención hallamos por el camino, salvo unas cuantas cruces negras marcando el lugar del asesinato de algún desgraciado. Es sobrecogedora la frecuencia con que se ven estas cruces-recordatorios del crimen por toda España. Yo mismo podría haber temido un destino similar si no fuera porque estaba lejos de este país - la mayoría de las cruces son de mucho tiempo hay porque hoy en día se puede viajar por España con la seguridad más absoluta.

Sobre las tres de la tarde, al descender por una colina, divisamos Loja, situada en un lugar muy pintoresco. Mientras contemplaba desde la galera tan bellísima vista, noté de pronto que la máquina aumentaba progresivamente su velocidad. La cadena de la narria - feo asunto este: se trata de una pieza de madera que, sujetada al árbol de ejes, impide mediante fricción que gire- la cadena de narria, digo, cedió y de repente nos precipitamos en una zanja que, afortunadamente, no era ni ancha ni profunda. La galera se inclinó pronto sobre su margen, pero nos llevó dos horas de trabajo sacarla de allí, y entonces se estimó que ya era demasiado tarde para proseguir nuestro viaje más allá de Loja. Parecía como si el destino no estuviera dispuesto a permitirnos alcanzar nuestra ansiosamente deseada Alhambra. Habiendo llegado por fin a la posada de este pueblo, mi compañero y yo nos dimos prisa por ver qué podía haber digno de atención en el lugar. Hallamos el pueblo limpio y bonito, con los balcones de las casas engalanados con macetas de rosas y otras flores; las muchachas llevaban una rosa prendida en el pelo, mientras que los hombres la llevaban en el sombrero; sólo flores naturales se pueden llevar como adorno en Andalucía. A la orilla del río que cruza el pueblo están los jardines públicos, de los que ninguna ciudad española carece. Lo que hicimos durante aquel atardecer no fue más que una mera repetición del anterior, y antes de romper el día estábamos de nuevo «en route» camino de Granada.

Aproximadamente a las 3 de la tarde entramos en una deliciosa vega y contemplamos a los lejos la ciudad de Granada, resplandeciendo bajo el sol de la 
tarde, con Sierra Nevada al fondo empinada entre nubes. Cruzamos Santa Fe, notable por ser el lugar donde Colón obtuvo el permiso del rey y la reina para proceder a la expedición en la que descubriera América. Conforme nos acercábamos a Granada fuimos contemplando las torres colgadas sobre la ciudad, hacia las que se dirigían nuestros pasos, todavía lejanos. En las afueras de la ciudad nos encontramos con unas parcelas de tierra cubiertas con las tumbas de las víctimas del cólera que ya ha terminado de asolar esta vega deleitosa que resistió su ataques hasta su última agonía. Ya ha desaparecido, sin embargo, y vamos a poder ver cómo todo discurre perfectamente. Si no hubiéramos sido detenidos tanto tiempo por el viento contrario y otras causas, probablemente hubiéramos llegado aquí en todo su apogeo.

Tras una corta espera en la casa de aduanas, y tras ser fastidiados un poco por un grupo de, digamos, nativos poco amistosos a quienes la vista de dos extranjeros perecía ser poco frecuente, pudimos al fin encontrar un cómodo alojamiento en la Fonda del Comercio, en otras palabras, «a commercial inn». Mi único deseo era en primer lugar tomar un baño caliente para purgarme de mis molestos inquilinos. Nuestra curiosidad nos sacó de la cama en hora temprana y subimos a la fortaleza siguiendo los paseos que serpentean colina arriba hasta donde está situada La Alhambra; finalmente, y tras una larga avenida de árboles, observamos una puerta imponente de estilo musulmán, que franqueaba la entrada a la fortaleza. La cruzamos maravillados y rebosantes de admiración y entramos en la gran plaza de la fortaleza, viendo a la derecha el inmenso palacio erigido por Carlos V sobre el que apenas si prestamos alguna atención, en cambio los dejamos atrás rápidamente y fuimos atraídos a nuestra derecha por un pequeño portillo que exteriormente no presentaba apariencia alguna de Elegancia. Al instante entramos en un patio inmenso con un estanque en su centro y con dos airosas y bellísimas arcadas en cada extremo, una de las cuales conducía al salón de embajadores y la otra al famoso patio de los leones. No hay nada que pueda dar una idea de la impresión que produce en el visitante la contemplación de estos salones, con sus arriates y fuentes. Arcadas y decoración damasquinada, ni una pulgada de pared que se vea, delicadísima ornamentación de dorados y de cualquier otra novedad de colorido, muchos, colores tan frescos como si fueran obra de ayer mismo, todo, en efecto, hace de este palacio algo tan perfecto que resulta difícil creer que haya podido soportar el peso de los siglos. Sólo la mano de una sultana desde la celosía del ventanal o un califa entre sueños rodeado por sus numerosos sirvientes sería necesario para darle vida a esta espléndida fortaleza. Es un verdadero desafío la tarea de intentar dar una idea de este edificio. Regresé a nuestros aposentos ligeramente febril por la excitación: Había visto demasiado. Sobre una colina frente a la de La Alhambra está el Generalife, la residencia de verano de los príncipes moros, el cual, aunque no tan bien conservado como $\mathrm{La}$ Alhambra, es un lugar maravilloso. La vista desde esta fortaleza sobre las llanuras circundantes es quizá inigualable.

Enseguida nos dispusimos a presentar nuestra solicitud al gobernador de La Alhambra, que reside en la ciudad, para que nos permitiera ocupar sus aposentos, que forman parte de La Alhambra, ya que la persona que está al cuidado 
del palacio se había ofrecido a tenernos como huéspedes. Tras muchas dificultades ha contestado a nuestra petición, y llevamos instalados aquí hace hace ahora una semana. Durante los tres o cuatro primeros días fuimos incapaces de hacer nada. Vagábamos por los salones de la mañana a la noche, examinando cada rincón y preguntándonos si seríamos capaces de conseguir algo alguna vez. Tal ha sido de la mayoría de las personas que han venido aquí con el propósito de estudio: han abandonado desesperadas ante el inmenso trabajo que tenían ante sí. Nosotros, sin embargo, hemos continuado y ahora nos encontramos en plena actividad. A las 5 de la mañana, en que sale el sol, descendemos por una pequeña escalera de caracol que está en la esquina de la torre de los guardas y en un momento nos hallamos en las cámaras de la una vez poderosa sultana. Cuando la familia se levanta nos bajan una taza de chocolate con tostada. A las diez tomamos el desayuno, y almorzamos a las cuatro; hacia las seis nos ponemos los sombreros y partimos para ver el «beau monde» de Granada. Sobre las ocho o las nueve regresamos a la cama, para prepararnos para la mañana. Disfrutando de la fresca brisa que continuamente juega entre sus paredes mientras la ciudad, abajo, se asfixia de calor. La situación de La Alhambra es tan saludable que cuando el cólera llegó a Granada ni un solo caso se dio entre la multitud de habitantes de la fortaleza, mientras que la ciudad sufrió de la manera más terrible, ni una sola familia dejó de perder alguno de sus miembros.

Como vais a poder ver por el corto tiempo en que esta carta llegará a vosotros, no estoy en un lugar tan distante. Esperamos dejar Granada dentro de un mes, con destino a Sevilla. Escribidme en contestación a ésta «poste restante Granada» y al mismo tiempo a Córdóba, en caso de que yo haya dejado este lugar antes de la llegada de vuestra carta. Espero carta vuestra cada día en respuesta a la mía desde Gibraltar, puesto que creo que una carta llega aquí desde Inglaterra en 10 días. Políticamente hablando todo está por aquí completamente tranquilo; de hecho podemos viajar por toda España con toda tranquilidad. Confío en que todos continueis bien. El momento de nuestro tan deseado encuentro se va aproximando y podéis empezar a prepararme unas cuantas camisas para cuando vuelva, pues yo sólo os llevaré remiendos. Casi se me olvidaba deciros que (a propósito, estoy seguro de que habréis leído los Cuentos de La Alhambra, de Washington Irving, que me enviasteis) la joven heroina de la que se relata la historia del halcón desobediente es nuestra patrona, con su tía: la Tía Antonia. Ahora está casada con su primo, como Irving había supuesto que ocurriría y tiene una niña pequeña, de cuatro años, que me recuerda mucho a Delaware tal como estaba cuando yo le dejé; pero ahora que ya es todo un hombre, ¿cómo va vestido? Ya os pregunté eso pero no me lo habéis dicho. Están también Manuel, y Mateo Ximénez, así como la vieja que contaba historias en las reuniones que se hacían al atardecer en casa de Tía Antonia. Me produjo un enorme placer encontrar a toda esta gente aquí. Como en los cuentos de Irving, están identificados con La Alhambra. Hay tal aliento en sus apuntes que sólo puede sentirse aquí, en su propio mundo. Ya ha pasado con mucho la hora en que normalmente me voy a la cama. Me acostaré para soñar con vosotras y sentir de nuevo el bálsamo de vuestros brazos ahí en Peckham. Debéis creerme muy cruel al resistirme de este modo 
a vuestra repetida súplica de que regrese, pero estoy seguro de que cuando nos veamos me diréis que he hecho bien. Dad mis cariñosos recuerdos a todos los amigos, sin olvidar a Del y su Papa. Excusadme ante todos ellos por no escribirles, procuraré compensarles debidamente cuando nos veamos.

Buenas noches. Adios.

Vuestro siempre cariñosamente.

OWEN JONES 
